\title{
Topic Modeling Penelitian Dosen JPTEI UNY pada Google Scholar Menggunakan Latent Dirichlet Allocation
}

\author{
Akhsin Nurlayli ${ }^{1}$, Moch. Ari Nasichuddin ${ }^{2}$ \\ ${ }^{1}$ Jurusan Pendidikan Teknik Elektronika dan Informatika, Universitas Negeri Yogyakarta; \\ ${ }^{2} \mathrm{PT}$. Atmatech Global Informatika \\ E-mail: akhsinnurlayli@uny.ac.id
}

\begin{abstract}
The mapping of research topics for lecturers is necessary to determine the research tendencies in a department or study program. This study aims to implement topic modeling in the publication titles of the Department of Electronics and Informatics Education Engineering of Universitas Negeri Yogyakarta (JPTEI UNY) lecturers taken from Google Scholar. The method used for topic modeling is the Latent Dirichlet Allocation (LDA). LDA is a generative probabilistic model for finding the semantic structure of a corpus collection based on the hierarchical bayesian analysis. After the topic modeling process, the results showed that JPTEI UNY lecturers tend to have four research clusters consisting of vocational education, system development, learning media, and vocational learning systems.
\end{abstract}

Keywords: clustering, LDA, research, topic modeling

\begin{abstract}
ABSTRAK
Pemetaan topik penelitian dosen diperlukan untuk mengetahui kecenderungan penelitian dosen pada suatu jurusan atau program studi. Penelitian ini bertujuan untuk mengimplementasikan topic modeling pada judul publikasi dari dosen Jurusan Pendidikan Teknik Elektronika dan Informatika (JPTEI UNY) yang diambil dari Google Scholar. Metode yang digunakan adalah Latent Dirichlet Allocation (LDA). LDA adalah model probabilistik generatif untuk mencari struktur semantik dari kumpulan korpus yang berdasarkan hierarchical bayesian analysis. Setelah dilakukan topic modeling, data hasil menunjukkan bahwa dosen JPTEI UNY cenderung memiliki judul penelitian tentang pendidikan vokasi, pengembangan sistem, media pembelajaran, dan sistem pembelajaran di SMK.
\end{abstract}

Kata kunci: clustering, LDA, penelitian, topic modeling

\section{PENDAHULUAN}

Penelitan menjadi entitas yang penting dalam dunia akademik. Kemajuan lini penelitian dapat dilihat dari segi jumlah penelitian dan arah topik penelitian yang dibahas. Untuk melihat arah penelitian perlu membaca satu persatu publikasi ilmiah dari seluruh dosen di sebuah instansi, kegiatan tersebut tentu akan memerlukan waktu dan tenaga. Oleh karena itu diperlukan suatu langkah yang bertujuan mengotomatisasi pembacaan arah topik penelitan dosen di suatu instansi akademik.
Langkah otomatisasi bisa dilakukan dengan pendekatan topic modeling. topic modeling merupakan suatu pendekatan untuk menganalisis kumpulan dokumen berbentuk teks dan mengelompokkan menjadi beberapa topik. Pendekatan tersebut masuk dalam pendekatan Clustering dalam studi Machine Learning.

Metode yang digunakan untuk melakukan pendekatan topic modeling bermacam-macam, yakni Latent Semantic Analysis (LSA), Probabilistic Latent Sematic Analysis (pLSA), Latent Dirichlet Allocation (LDA), dan lain-lain [1]. Contoh beberapa penelitian sebelumnya yang melakukan topic modeling, yakni 
penerapan topic modeling untuk menggambarkan topik mengenai kondisi cuaca dan iklim di Pulau Jawa berdasarkan data dari twitter BMKG (Badan Meteorologi, Klimatologi, dan Geofisika) [2], penerapan topic modeling untuk menghasilkan topik atau klaster secara semantik agar mampu merangkum keluhan konsumen pada Biro Perlindungan Keuangan Konsumen di Amerika [3], penerapan topic modeling menggunakan LDA untuk mendeteksi keadaan darurat perkotaan di Virginia menggunakan data yang dikumpulkan dari Twitter [4], penerapan topic modeling untuk analisis topik dari domain penelitian di University of Kentucky [5], penerapan topic modeling untuk klasifikasi ketertarikan penelitian berdasarkan data abstrak pada publikasi [6], penerapan topic modeling menggunakan LDA untuk menautkan usergenerated content dan data e-commerce [7], pemodelan penyebaran informasi multi-topik di jejaring sosial menggunakan LDA dan proses Hawkes [8], penerapan topic modeling menggunakan LDA dalam pelabelan posting blog pada Wikipedia [9], penerapan topic modeling pada klasifikasi teks dataless multilabel [10]. Adapun penelitian terhadap perkembangan topic modeling menunjukkan bahwa LDA merupakan metode yang telah membuat dampak besar di bidang Natural Language Processing (NLP) dan machine learning, sehingga dengan cepat menjadi salah satu teknik topic modeling yang paling populer dalam machine learning. [1], [11].

Berdasarkan hasil analisis beberapa penelitian pada topic modeling, kami menggunakan metode LDA yang merupakan state-of-the-art [1], [6], [11] dalam pemodelan topik penelitian dosen berdasarkan data judul publikasi masing-masing dosen yang diambil dari Google Scholar. Setelah data diproses menggunakan LDA, hasilnya menunjukkan apa saja topik penelitian yang dibahas, kata-kata apa saja yang digunakan untuk penelitian, dan apa saja topik yang sering dibahas oleh dosen Jurusan Pendidikan Teknik Elektronika dan Informatika (JPTEI UNY).

\section{METODE}

\section{Data Retrieval}

Dataset diambil dari akun masing-masing dosen Jurusan Pendidikan Teknik Elektronika dan Informatika Universitas Negeri Yogyakarta (JPTEI UNY) pada Google Scholar. Google Scholar merupakan repository yang berisi publikasi dari hasil penelitian-penelitian yang telah dilakukan. Pengambilan data dilakukan menggunakan teknik scrapping yang dibantu oleh ekstensi Google Chrome bernama Web Scrapper. Hasil scrapping disimpan dalam format .csv dan data yang didapatkan adalah 909 judul publikasi.

\section{Data Pre-Processing}

Data Pre-Processing dibutuhkan untuk menghasilkan data clustering yang tepat. Berikut adalah data pre-processing yang dilakukan: (1) Mengubah kalimat menjadi kata; Menghilangkan beberapa kata dalam Bahasa Indonesia dan Bahasa Inggris yang tidak memiliki arti. Kata dalam Bahasa Inggris misalnya: using, of, the in, on, as, and, based, dan lain-lain. Kata dalam Bahasa Indonesia misalnya: berbasis, kasus, dan, pada, dan lainlain. (3) Mengubah susunan suatu kalimat menjadi dalam bentuk bigram, misalnya: "Inovasi Media Pembelajaran Sain Teknologi di SMP Berbasis Mikrokontroler", ketika diubah menjadi bigram: [inovasi, media], [pembelajaran, sain], [teknologi, di], [SMP, berbasis], [mikrokontroller].

\section{Topic Modeling}

Topic Modeling atau pemodelan topik adalah sebuh metode unsupervised machine learning yang menerapkan pengelompokan untuk menemukan variable laten dari data teks yang besar. Metode yang paling populer untuk pemodelan topik adalah Latent Dirichlet Allocation ( $L D A$ ) yang diperkenalkan oleh Blei dan Jordan, dijelaskan sebagai model probabilistik generatif untuk mencari struktur semantik dari kumpulan korpus yang berdasarkan hierarchical bayesian analysis [8]. LDA merupakan kumpulan dokumen sebagai topik campuran yang berisi kata-kata dengan 
probabilitas tertentu. Adapaun alur kerja dari LDA dapat dilihat pada Gambar 1.

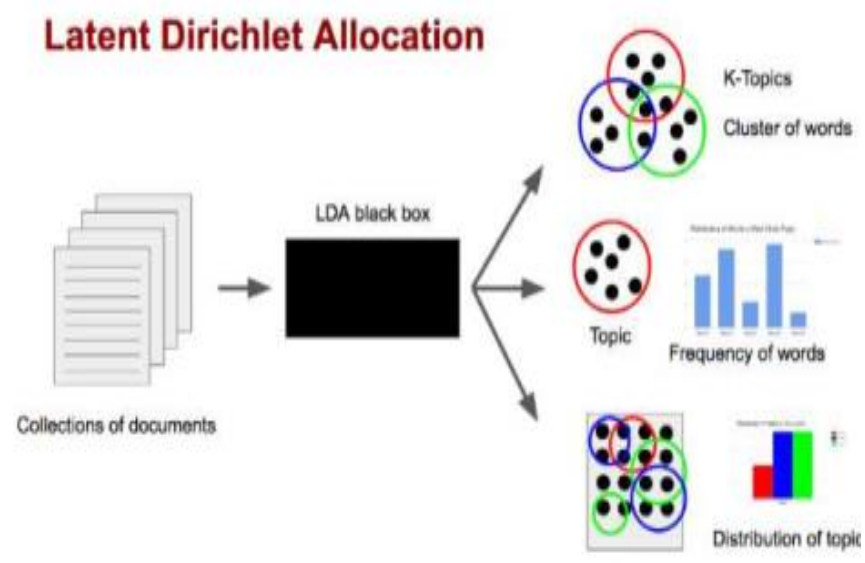

Gambar 1. Alur Kerja LDA [2]

Prosedur cara kerja LDA adalah sebagai berikut: (1) Inisialisasi beberapa parameter, termasuk jumlah dokumen, topik, dan iterasi. Dalam LDA, parameter yang paling penting adalah jumlah topik k. (2) Menetapkan kata untuk topik tertentu secara acak sesuai dengan distribusi dirichlect. (3) Mengulangi masingmasing alur proses untuk semua kata dalam korpus.

Parameter yang digunakan ketika proses perhitungan LDA sebagai berikut: (1) Random state: 100; (2) Update Every: 1; (3) Chunk Size: 10; (4) Passes: 10; (5) Alpha: Symmetric; (6) Iterations: 100; (7) Per Word Topics: True

Dalam menentukan jumlah topik alat ukur yang dipergunakan adalah coherence value. Pada penelitian kali dari percobaan menggunakan 1-9 topik, nilai coherence value yang didapat sama, yaitu 0,4076. Dari nilai tersebut maka penelitian ini menentukan banyaknya topik secara acak, yaitu 4 .

\section{HASIL DAN PEMBAHASAN}

Penelitian ini mengelompokkan topik penelitian berdasarkan data publikasi dosen JPTEI pada Google Scholar ke dalam empat klaster topik. Visualisasi kata yang muncul pada empat klaster data tersebut dapat dilihat pada Gambar 2.

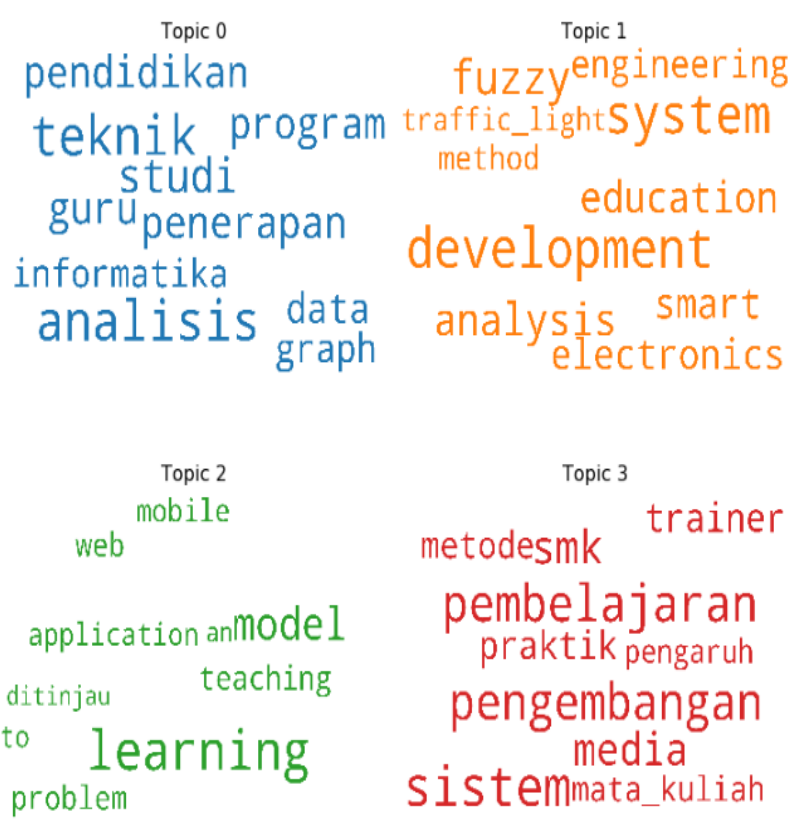

Gambar 2.Visualisasi Kata

Gambar 2. Menunjukkan bahwa pada Klaster ke-1 (Topic 0) berisi kata tentang Pendidikan, tenik, informatika, analisis, graph, dan sebagainya. Dari kata yang muncul pada Klaster ke-1 dapat interpretasikan berbicara tentang Pendidikan Vokasi.

Pada Klaster ke-2 (Topic 1) mengandung kata electronics, development, education, system, method, dan sebagainya. Dari kata yang muncul pada Klaster ke-2 dapat interpretasikan berbicara tentang Pengembangan Sistem.

Sedangkan pada Klaster ke-3 (Topic 2) adalah mobile, web, model, teaching, problem, dan lain-lain. Dari kata yang muncul pada Klaster ke-3 dapat interpretasikan berbicara tentang Media Pembelajaran.

Dan pada Klaster ke-4 (Topic 3) mengandung kata SMK, trainer, pembelajaran, praktik, dan lain sebagainya. Dari kata yang muncul pada Klaster ke-4 dapat interpretasikan berbicara tentang Sistem Pembelajaran di SMK.

Interpretasi di atas diperkuat dengan adanya visualisasi jumlah masing-masing kata yang muncul pada masing setiap topik (Gambar $3)$. 

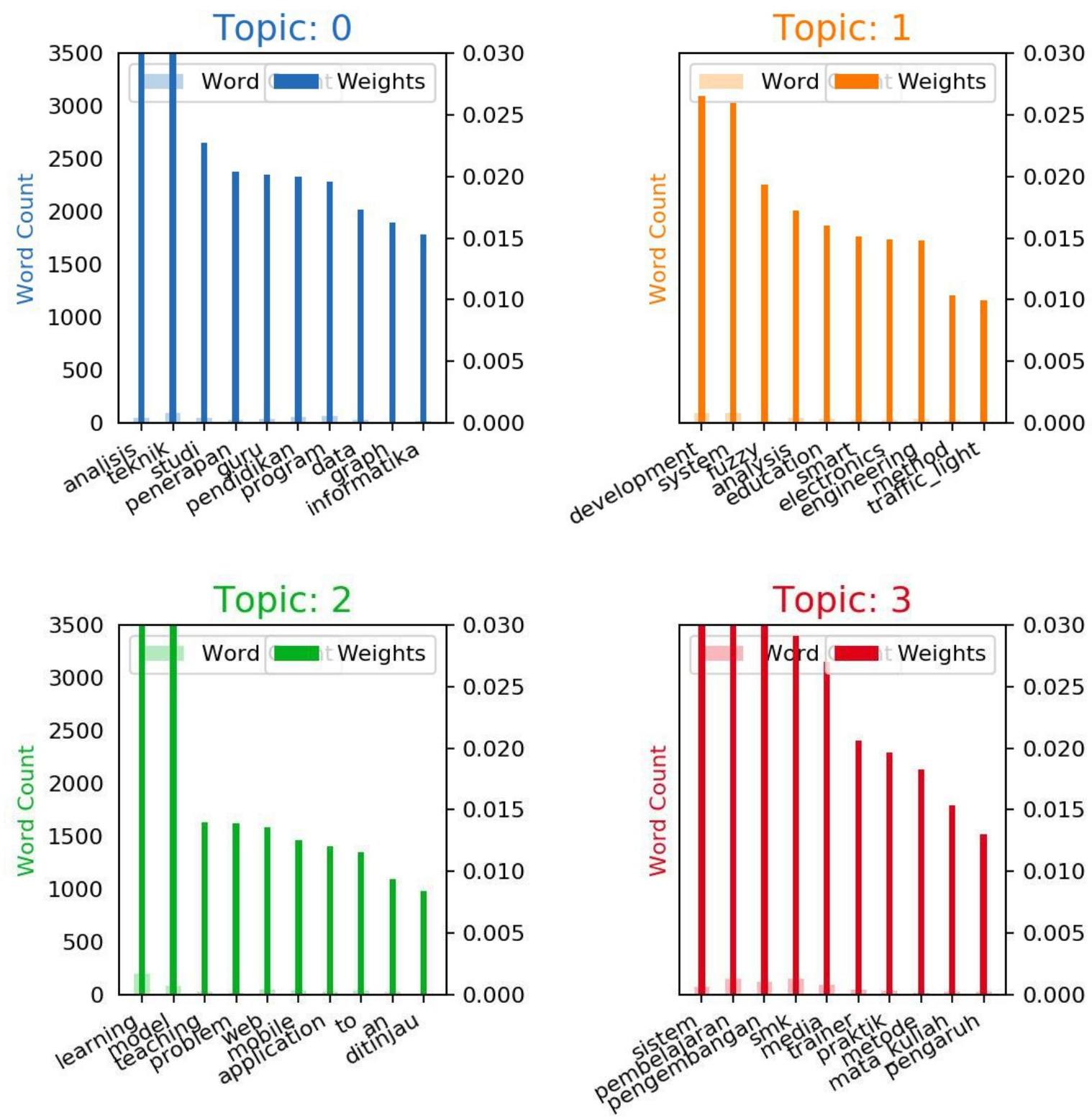

Gambar 3. Visualisasi Jumlah Kata

Gambar 3. menunjukkan kata yang sering muncul pada Klaster ke-1 (Topic 0) adalah Analisis, Teknik, Studi, Penerapan, Guru, Pendidikan, dan Program. Klaster ke-2 (Topic 1) adalah Development, System, Fuzzy, Analysis, Education, dan Smart. Klaster ke-3 (Topic 2) adalah Learning, Model, Teaching, Problem, dan Web. Klaster ke-4 (Topic 3) adalah Sistem, Pembelajaran, Pengembangan, SMK, Media, dan Trainer.

Jika kita lihat secara keseluruhan pada Gambar 3, kata yang sering dipakai untuk judul adalah Analisis, Teknik, Development, System,
Learning, Model, Sistem, Pembelajaran, Pengembangan, SMK, Media, dan Trainer.

Lebih detail lagi beberapa contoh judul penelitian dapat dilihat pada setiap klaster atau topik. Judul-judul penelitian pada keempat topik dapat dilihat pada Tabel 1, 2, 3, dan 4. Judul penelitian yang masuk dalam Klaster ke-1 (Topic 0) dapat dilihat pada Tabel 1. 
Tabel 1. Judul Penelitian pada Klaster ke-1 (Topic 0)

\begin{tabular}{l}
\hline \multicolumn{1}{c}{ Klaster ke-1 (Topic 0) } \\
\hline Analisis penerapan sistem informasi \\
akademik (siakad) 2013 menggunakan model \\
end-user computing satisfaction (eucs) di \\
program studi pendidikan teknik informatika \\
Penerapan problem based learning untuk \\
higher order thinking skills pada siswa \\
pendidikan teknik informatika \\
Speech recognizing for presentation tool \\
navigation using back propagation artificial \\
neural network \\
Studi penelusuran (tracer study) terhadap \\
alumni program studi pendidikan teknik \\
informatika jurusan pendidikan teknik \\
elektronika fakultas teknik universitas negeri \\
yogyakarta \\
Studi Penelusuran Alumni Teknik \\
Elektronika D3 sebagai Upaya Peningkatan \\
Mutu Penyelenggaraan Program Studi
\end{tabular}

Judul penelitian yang masuk dalam Klaster ke-2 (Topic 1) dapat dilihat pada Tabel 2.

Tabel 2. Judul Penelitian pada Klaster ke-2 (Topic 1)

\begin{tabular}{l}
\hline \multicolumn{1}{c}{ Klaster ke-2 (Topic 1) } \\
\hline Smart Traffic Light based on IoT and mBaaS \\
using High Priority Vehicles Method \\
E-module Development for the Subject of \\
Measuring Instruments and Measurement in \\
Electronics Engineering Education \\
Aplikasi Platform Komputasi Software- \\
Defined Radio (SDR) untuk Digital \\
Spectrum Analizer \\
Android-based applications on teaching \\
skills based on TPACK analysis \\
Smart System for Lung Disease Early \\
Detection
\end{tabular}

Judul penelitian yang masuk dalam Klaster ke-3 (Topic 2) dapat dilihat pada Tabel 3.
Tabel 3. Judul Penelitian pada Klaster ke-3 (Topic 2)

\begin{tabular}{l} 
Klaster ke-3 (Topic 2) \\
\hline The development of mobile gamification \\
learning application for web programming \\
learning \\
Multi-connection phone-based mobile \\
internet to support e-learning and ict literacy \\
for rural community \\
Mobile internetberbasis a multiconally \\
mobile phone for supporting e-learning \\
Design of interaction model for interactive e- \\
book \\
Collaborative learning model with computer \\
supported learning approach \\
$\quad$ Judul penelitian yang masuk dalam \\
Klaster ke-4 (Topic 3) dapat dilihat pada Tabel \\
4. \\
Tabel 4. Judul Penelitian pada Klaster ke-4 \\
(Topic 3) \\
\hline Klaster ke-4 (Topic 3) \\
\hline Trainer PID Controller sebagai Media \\
Pembelajaran Praktik Sistem Kendali \\
Pengembangan Trainer Internet Of Things \\
Sebagai Media Pembelajaran Pada Mata \\
Kuliah Internet Of Things \\
Pengembangan Trainer Signal Conditioning \\
Pengembangan Media Pembelajaran Trainer \\
Audio Power Amplifier OCL Dilengkapi VU \\
Meter Dan Protektor Speaker Untuk Mata \\
Pelajaran Perekayasaan Sistem Audio Di SMK \\
Negeri 1 Magelang 1 \\
Peningkatan Kualitas Pembelajaran Praktik \\
Study \\
\hline
\end{tabular}

Dari segi penulis pada setiap topik, dapat dilihat pada Tabel 5, 6, 7, dan 8. Sepuluh penulis dengan jumlah judul penelitian terbanyak pada Klaster ke-1 (Topic 0) dapat dilihat pada Tabel 5. 
Tabel 5. Nama Penulis pada Klaster ke-1 (Topic 0)

\begin{tabular}{lc}
\hline Nama & Jumlah Penelitian \\
\hline Putu Sudira & 28 \\
Soenarto & 28 \\
Herman Dwi Surjono & 17 \\
Fatchul Arifin & 13 \\
Adi Dewanto & 10 \\
Pramudi Utomo & 9 \\
Handaru Jati & 8 \\
Dessy Irmawati & 7 \\
Sri Waluyanti & 5 \\
Eko Marpanaji & 5 \\
\hline
\end{tabular}

Sepuluh penulis dengan jumlah judul penelitian terbanyak pada Klaster ke-2 (Topic 1) dapat dilihat pada Tabel 6 .

Tabel 6. Nama Penulis pada Klaster ke-2 (Topic 1)

\begin{tabular}{lc}
\hline Nama & Jumlah Penelitian \\
\hline Adi Dewanto & 21 \\
Soenarto & 21 \\
Handaru Jati & 21 \\
Totok Sukardiyono & 20 \\
Sri Waluyanti & 17 \\
Suprapto & 15 \\
Nurkhamid & 15 \\
Herman Dwi Surjono & 13 \\
Eko Marpanaji & 12 \\
Dessy Irmawati & 12 \\
\hline
\end{tabular}

Sepuluh penulis dengan jumlah judul penelitian terbanyak pada Klaster ke-3 (Topic 2) dapat dilihat pada Tabel 7.

Tabel 7. Nama Penulis pada Klaster ke-2 (Topic 1)

\begin{tabular}{lc}
\hline Nama & Jumlah Penelitian \\
\hline Herman Dwi Surjono & 44 \\
Soenarto & 33 \\
Handaru Jati & 26 \\
Priyanto & 15 \\
Fatchul Arifin & 11 \\
Nurkhamid & 9 \\
Totok Sukardiyono & 8 \\
Sri Waluyanti & 7 \\
Pipit Utami & 5 \\
Suprapto & 5 \\
\hline
\end{tabular}

Sepuluh penulis dengan jumlah judul penelitian terbanyak pada Klaster ke-4 (Topic 3) dapat dilihat pada Tabel 8.

Tabel 8. Nama Penulis pada Klaster ke-4 (Topic 3)

\begin{tabular}{lc}
\hline Nama & Jumlah Penelitian \\
\hline Herman Dwi Surjono & 44 \\
Soenarto & 34 \\
Sri Waluyanti & 18 \\
Putu Sudira & 17 \\
Fatchul Arifin & 17 \\
Bekti Wulandari & 13 \\
Handaru Jati & 12 \\
Eko Marpanaji & 11 \\
Umi Rochayati & 11 \\
Djoko Santoso & 10 \\
\hline
\end{tabular}

Dari Tabel 5, 6, 7, dan 8 menunjukkan bahwa Herman Dwi Surjono menjadi penulis terbanyak di Klaster ke-3 (Topic 2) dan Klaster ke-4 (Topic 3). Adi Dewanto, Soenarto, dan Handaru Jati menjadi penulis terbanyak di Klaster ke-2 (Topic 1). Putu Sudira dan Soenarto menjadi penulis terbanyak di Klaster ke-1 (Topic 0 ). Khusus untuk Soenarto, beliau memiliki jumlah publikasi cukup banyak di masingmasing topik. 28 judul penelitian pada Klaster ke-1 (Topic 0), 21 judul penelitian pada Klaster ke-2 (Topic 1), 33 judul penelitian pada Klaster ke-3 (Topic 2), 34 judul penelitian pada Klaster ke-4 (Topic 3).

Berdasarkan hasil pengelompokan Klaster 1, 2, 3, dan 4 ditemukan adanya keterkaitan antar klaster atau topic. Pada Gambar 4. menunjukkan visualisasi keterkaitan antar klaster atau topic. 


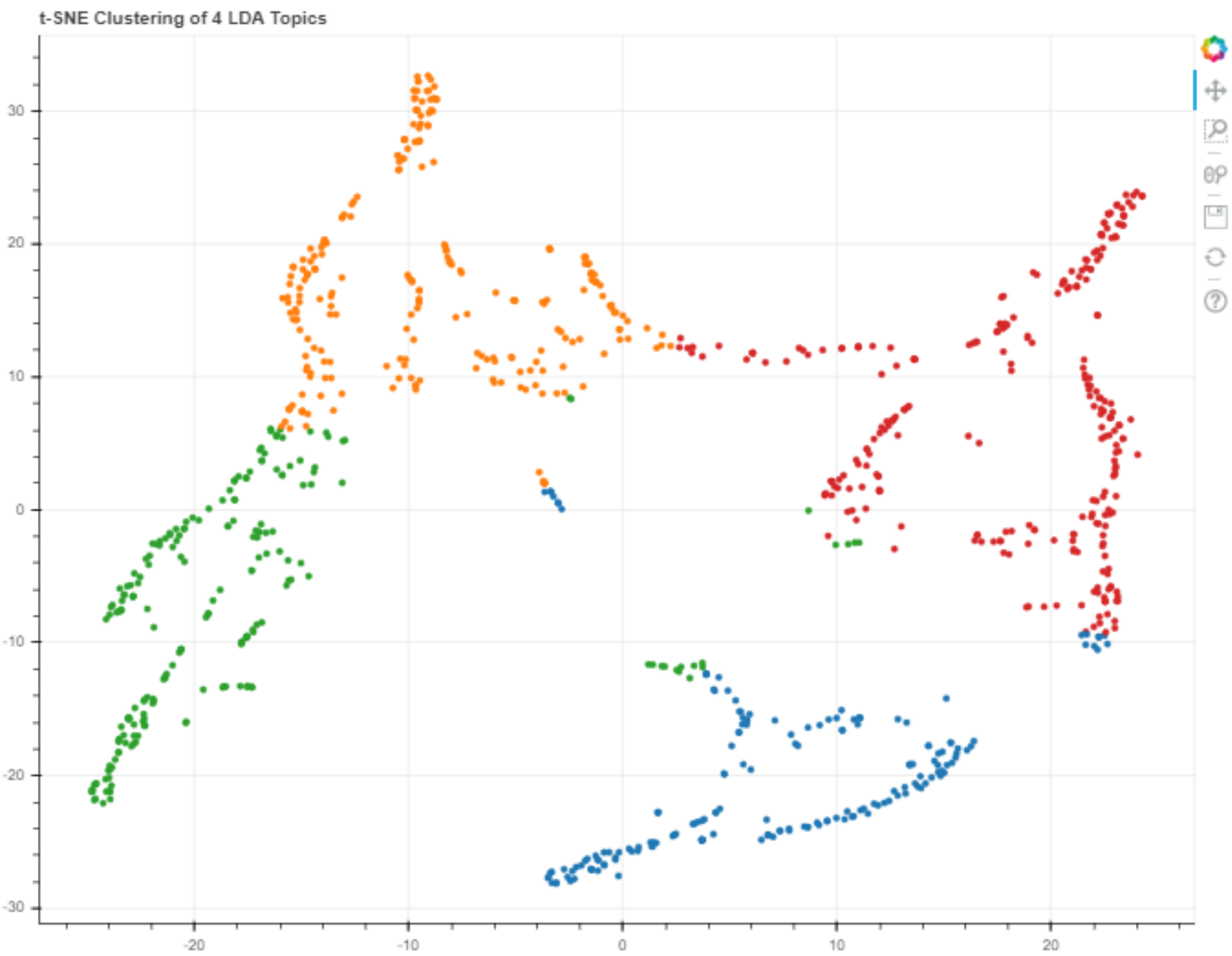

Gambar 4. Keterkaitan antar Klaster atau Topic

Dari segi keterkaitan antar klaster atau topic (Gambar 4.), Klaster ke-4 (Topic 3) yang berwarna merah, Klaster ke-2 (Topic 1) yang berwarna oranye, dan Klaster ke-3 (Topic 2) yang berwarna hijau saling memiliki keterkaitan. Hal ini karena Klaster ke-2 (Topic 1) dan Klaster ke-3 (Topic 2) memiliki banyak kata berbahasa Inggris. Klaster ke-1 (Topic 0) yang berwarna biru meskipun menjadi klaster atau topic terbesar, ternyata cenderung minim keterkaitan dengan klaster yang lainnya.

\section{SIMPULAN}

Pada penelitian ini telah menerapkan pemodelan topik menggunakan LDA (Latent Dirichlet Allocation) pada data judul penelitian dosen JPTEI UNY yang telah terpublikasi dan ada pada Google Scholar. LDA telah menjadi algoritme yang baik dalam pemodelan topik dan telah dibuktikan pada beberapa penelitian terkait pemodelan topik.
Berdasarkan hasil penelitian kami, hasil yang paling optimum adalah pengelompokan data judul penelitian menjadi empat klaster atau empat topik. Sehingga dapat disimpulkan bahwa topik penelitian dosen JPTEI UNY adalah tentang pendidikan vokasi (Klaster ke-1/Topic 0 ), pengembangan system (Klaster ke-2/Topic 1), media pembelajaran (Klaster ke-3/Topic 2), dan sistem pembelajaran di SMK (Klaster ke4/Topic 3). Jumlah penelitian dosen JPTEI UNY paling banyak adalah pada Klaster ke-1 dan paling sedikit adalah pada Klaster ke-4.

Adapun kelemahan dalam penelitian ini adalah belum adanya pendekatan khusus untuk teks tidak berbahasa Indonesia pada proses preprocessing. Sehingga untuk penelitian selanjutnya, diperlukan optimalisasi pada data pre-processing. 


\section{REFERENSI}

[1] R. Alghamdi and K. Alfalqi, "A Survey of Topic Modeling in Text Mining," Int. J. Adv. Comput. Sci. Appl., vol. 6, no. 1, pp. 147-153, 2015.

[2] A. F. Hidayatullah, S. K. Aditya, Karimah, and S. T. Gardini, "Topic modeling of weather and climate condition on twitter using latent dirichlet allocation (LDA)," IOP Conf. Ser. Mater. Sci. Eng., vol. 482, no. 1, 2019.

[3] K. Bastani, H. Namavari, and J. Shaffer, "Latent Dirichlet allocation (LDA) for topic modeling of the CFPB consumer complaints," Expert Syst. Appl., vol. 127, pp. 256-271, 2019.

[4] Y. Wang and J. E. Taylor, "DUET: DataDriven Approach Based on Latent Dirichlet Allocation Topic Modeling," J. Comput. Civ. Eng., vol. 33, no. 3, 2019.

[5] S. Joo, I. Choi, and N. Choi, "Topic analysis of the research domain in knowledge organization: A latent dirichlet allocation approach," Knowl. Organ., vol. 45, no. 2, pp. 170-183, 2018.

[6] S. W. Kim and J. M. Gil, "Research paper classification systems based on TF-IDF and LDA schemes," Human-centric Comput. Inf. Sci., vol. 9, no. 1, 2019.

[7] S. Zoghbi, I. Vulić, and M. F. Moens, "Latent Dirichlet allocation for linking user-generated content and e-commerce data," Inf. Sci. (Ny)., vol. 367-368, pp. 573-599, 2016.

[8] J. C. L. Pinto and T. Chahed, "Modeling multi-topic information diffusion in social networks using latent dirichlet allocation and hawkes processes," Proc. - 10th Int. Conf. Signal-Image Technol. Internet-Based Syst. SITIS 2014, pp. 339-346, 2015.

[9] D. Yokomoto et al., "LDA-based topic modeling in labeling blog posts with wikipedia entries," Lect. Notes Comput. Sci. (including Subser. Lect. Notes Artif. Intell. Lect. Notes Bioinformatics), vol. 7234 LNCS, pp. 114-124, 2012.

[10] D. Zha and C. Li, "Multi-label dataless text classification with topic modeling," Knowl. Inf. Syst., vol. 61, no. 1, pp. 137160, 2019.
[11] H. Jelodar et al., "Latent Dirichlet allocation (LDA) and topic modeling: models, applications, a survey," Multimed. Tools Appl., vol. 78, no. 11, pp. 15169-15211, 2019. 